JPE 10-5-12

\title{
Wind Power Grid Integration of an IPMSG using a Diode Rectifier and a Simple MPPT Control for Grid-Side Inverters
}

\author{
Tarek Ahmed ${ }^{\dagger}$, Katsumi Nishida*, and Mutsuo Nakaoka** \\ $\dagger$ Dept. of Electrical and Electronics, Faculty of Engineering, Assiut University, Assiut, Egypt \\ * Dept. of Electric Machines, Ube National College of Technology, Ube City, Yamaguchi, Japan \\ ** The Electric Energy Saving Research Center, Kyungnam University, Masan, South Korea
}

\begin{abstract}
In this paper, a $1.5 \mathrm{~kW}$ Interior Permanent Magnet Synchronous Generator (IPMSG) with a power conditioner for the grid integration of a variable-speed wind turbine is developed. The power-conditioning system consists of a series-type 12-pulse diode rectifier powered by a phase shifting transformer and then cascaded to a PWM voltage source inverter. The PWM inverter is utilized to supply sinusoidal currents to the utility line by controlling the active and reactive current components in the q-d rotating reference frame. While the $q$-axis active current of the PWM inverter is regulated to follow an optimized active current reference so as to track the maximum power of the wind turbine. The $d$-axis reactive current can be adjusted to control the reactive power and voltage. In order to track the maximum power of the wind turbine, the optimal active current reference is determined by using a simple MPPT algorithm which requires only three sensors. Moreover, the phase angle of the utility voltage is detected using a simple electronic circuit consisting of both a zero-crossing voltage detecting circuit and a counter circuit employed with a crystal oscillator. At the generator terminals, a passive filter is designed not only to decrease the harmonic voltages and currents observed at the terminals of the IPMSG but also to improve the generator efficiency. The laboratory results indicate that the losses in the IPMSG can be effectively reduced by setting a passive filter at the generator terminals.
\end{abstract}

Key Words: Diode Rectifier, Interior Permanent Magnet Synchronous Generator, Passive Filter, PWM Inverter, Wind Energy

\section{INTRODUCTION}

Operation at an optimum speed in response to wind velocity minimizes fluctuations in power output and their effects on the power grid. Compared with conventional wind turbines, many improvements are required in performance and reliability to achieve higher economic efficiency and to promote the introduction of wind power generation [1]-[3]. Consequently, large scale wind turbines employing pitch control, variable-speed control and a permanent magnet synchronous generator are increasingly viable. It has been concluded in previous research that the combination of a permanent magnet synchronous generator and an inverter/converter allows the fluctuations in wind turbine output and the voltage variations to be greatly reduced. Further, there is no rush current when the generator is incorporated into the power grid system [4]-[6].

In order to work as a stand-alone power supply in a remote area, a bulky energy storage system is needed for sustainable production and operation of a variable-speed wind turbine

Manuscript received Feb. 25, 2010; revised Jul. 18, 2010

† Corresponding Author: tarekahmed@ieee.org

Tel:+2-0237717986, Fax:+2-0235856819, Assiut University

* Dept. of Electric Machines, Ube National College of Technology, Japan

** The Electric Energy Saving Research Center, Kyungnam University, South Korea
[7]-[10]. Therefore, a power-conditioner is required for wind power to be integrated into the grid. However, a full power controlled converter is expensive. In terms of the use of a synchronous generator, a simple alternative scheme is used when a generator-side converter is replaced by a three-phase diode rectifier and a chopper [11]-[15]. This scheme is low cost when compared with a full power converter. When the speed of the generator changes, the voltage value on the dc side of the diode rectifier will also change. A step-up chopper is used to adapt the rectifier voltage to the dc-link voltage of the inverter [10]. The step-up chopper used as a rectifier utilizes a high switching frequency implying that the bandwidth of these components is much higher than the bandwidth of the generator. Controlling the inductance current in the step-up converter can control the machine torque and therefore its speed. However, this method generates high voltage surges on the generator windings and thus reduces the life span of the generator especially in a high power wind turbine system. In [14], a buck-boost converter is proposed for a dcdc chopper and the output current reference of the chopper is designed for the maximum power point tracking of a wind turbine. However, the voltage stress of the chopper switch is greater than that of the boost converter. In addition, the leakage inductance of the generator and the cable cannot be used as 


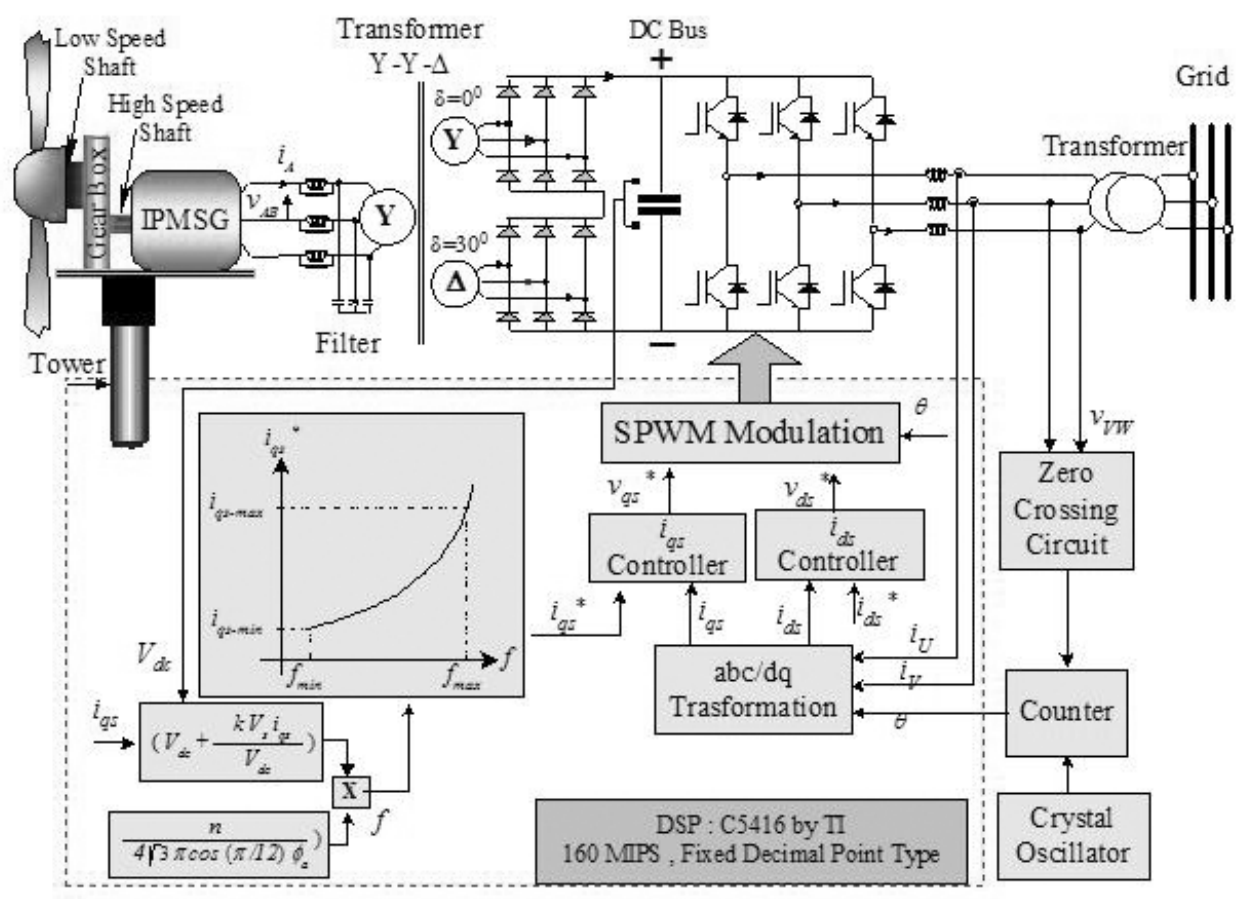

Fig. 1. A series-type 12 pulse rectifier and PWM inverter for wind power generation system.

an equivalent dc inductor.

In this paper, a power electronic interface consisting of a series-type 12 pulse rectifier and a three-phase voltagefed PWM inverter with a simple MPPT control strategy for IPMSG-wind power grid integration is developed. The gridside PWM inverter is able to supply sinusoidal currents to the power grid within a wide range of the system speed operation. The power factor of the grid-side PWM inverter can be adjusted by controlling its reactive current control. However, the reference for the active current of the grid-side inverter is set for the maximum power point tracking of the wind turbine. The most significant advantages of the proposed system are that the passive filter together with a series-type 12pulse rectifier provide high efficiency and suppress distortions present in the IPMSG voltage and current. The results of a $1.5 \mathrm{~kW}$ generator indicate that the construction and installation of the proposed system are simple and reliable.

\section{SYSTEM DESCRIPTION}

Fig. 1 shows the schematic of a full power converter for a variable-speed wind power generation system. The proposed power-conditioning system, connected to an interior permanent magnet synchronous generator (IPMSG) driven by a wind turbine, consists of a series-type 12 pulse rectifier and an inverter. The 12 pulse rectifier is powered by a $\mathrm{Y} / \mathrm{Y} / \Delta$ transformer with a turns ratio of $2: 1: \sqrt{ } 3$, where the secondary line to line voltages have the same value. The three-phase voltagefed PWM inverter is connected to the power grid through three-phase transformers. The grid-side inverter is controlled for achieving MPPT control by controlling its $q$-axis active current component. The current reference is set to achieve the desired MPPT scheme which results in the maximum active power being supplied to the grid from the wind turbine. In addition, the $d$-axis reactive current can be adjusted to control the reactive power. The current controller has fast response as it works in the $d-q$ axis synchronous reference frame.

Moreover, it is possible to have high generator efficiency by connecting a passive generator filter to the generator terminals. The passive filters, represented by $L_{s}$ and $C_{s}$, are designed to compensate the harmonic currents produced by a seriestype 12-pulse diode rectifier and to smooth the ripple on the generated compensation voltages. In addition, to reduce the harmonic content, the total losses in the stator winding of the IPMSG can be reduced in order to improve the generator efficiency.

\section{CHARACTERISTICS OF THE WIND TURBINE}

Normally, a variable speed wind turbine follows the maximum power coefficient $C_{o p t}$, to capture the maximum power up to its rated speed by varying the rotor speed to keep the system at the optimum tip speed ratio $\lambda_{o p t}$. Then, it operates at the rated power with power regulation during periods of high wind by active control of the blade pitch angle or by passive regulation based on aerodynamics stall. The optimum output power $P_{o p t}$ of the wind turbine can be defined as a function of the generator frequency and is expressed by:

$$
P_{o p t}=K_{o p t} f^{3}
$$

where, $f$ is the generator frequency which is proportional to the rotational speed of the generator and $K_{o p t}$ is given by: 


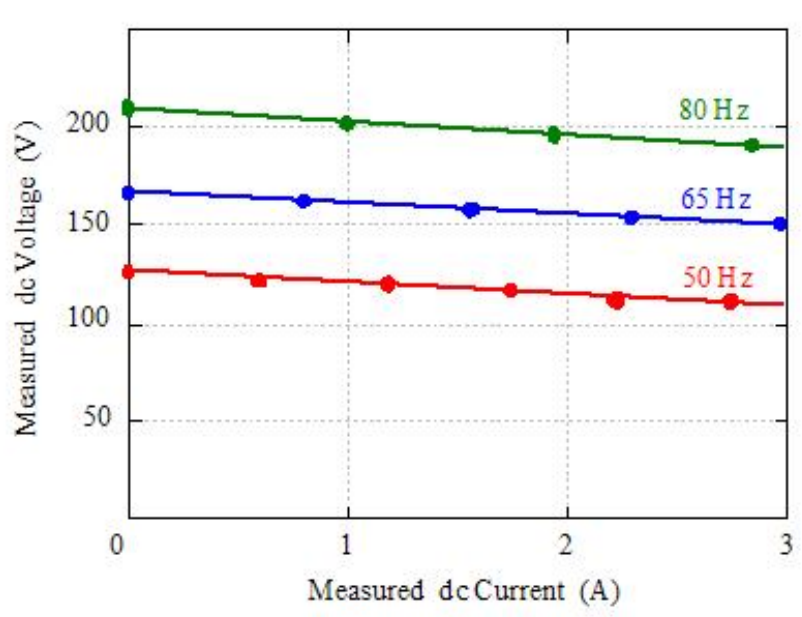

Fig. 2. Linear characteristics of IPMSG with series-type 12 pulse rectifier.

$$
K_{o p t}=\frac{1}{2} \rho \pi R^{2} C_{o p t} \eta_{g} \eta_{b}\left(\frac{2 \pi R}{p_{n} \lambda_{o p t}}\right)^{3}
$$

where $\rho$ is the air density $\left(\mathrm{kg} / \mathrm{m}^{3}\right), R$ is the turbine radius $(m), \eta_{g}$ is the generator efficiency, $\eta_{b}$ is the gearbox/bearings efficiency and $p_{n}$ is the number of pair poles of the generator. The maximum output power of the wind turbine determines the characteristic load line of the generator. If the wind speed increases, the turbine speed will increase because of the differences in the generated and load torques. Then a new operating point will be decided on the characteristic line, where the load and generation torques are equal.

\section{A. MPPT Control for PWM Inverter}

Fig.2 indicates the experimental results of the dc-link voltage of a series-type 12 pulse rectifier under dc load and speed variations. The results indicated that the relation between the dc-link voltage and current is linear and is given experimentally as:

$$
V_{d c}=-k I_{d c}+V_{d c 0}
$$

where $V_{d c}$ is the measured dc-link voltage of the series-type 12 pulse rectifier, $V_{d c 0}$ is the dc-link voltage under the no-load condition, $I_{d c}$ is the dc-link current and $k(k=5.6 \mathrm{~V} / \mathrm{A})$ is a constant.

Based on the experimental results represented by eq.3, the dc-link voltage $V_{d c 0}$ under the no-load condition is estimated using both the measured dc-link voltage $V_{d c}$ and the dc-link current $I_{d c}$. The $V_{d c 0}$, which is required to determine the generator frequency $f$, is calculated based on the rotational speed of the generator and obtained from the filtered dc output voltage of the diode rectifier. As the rectifier is a series 12 pulse type, the generator frequency is defined by:

$$
f=\frac{n}{4 \sqrt{3} \pi \cos \left(\frac{\pi}{12}\right)}\left(\frac{V_{d c 0}}{\phi_{a}}\right)
$$

where, $\phi_{a}$ is the magnet flux-linkage of the IPMSG $\left(\phi_{a}=0.235\right.$ $\mathrm{Wb})$ ) and $\mathrm{n}(\mathrm{n}=2)$ is the transformer turns ratio.

The current reference $I_{d c}^{*}$ of the grid-side converter is calculated from the predetermined maximum output power of the wind turbine according to the generator frequency. As a result, the wind turbine can generate the maximum output power. By neglecting the power losses and making the power balance between the optimum output power of the turbine defined by eq. 1 and the dc power supplied to the grid-side inverter, the dc current reference $I_{d c}^{*}$ of the generator-side converter is defined as:

$$
I_{d c}^{*}=\frac{K_{o p t}}{V_{d c}} f^{3} .
$$

In order to demonstrate simply the function of the passive filter and investigate the significant advantages of the proposed MPPT algorithm, Fig. 1 is used to implement the system in the lab. A series-type 12-pulse diode rectifier, powered by a phase shifting transformer is directly cascaded to the PWM inverter. The dc-link current is calculated by making the power balance between the dc-link power and the power supplied to the grid while neglecting the power losses in the grid-side PWM inverter. The $d c$ current $I_{d c}$ is defined by:

$$
I_{d c}=\frac{V_{s}}{V_{d c}} i_{q s}
$$

where $i_{q s}$ is the measured active current of the inverter and $V_{s}$ is the rms value of the line-to-line voltage of the grid. The generator frequency is given by eq. 4 and the current reference $i_{q s}^{*}$ of the grid-side converter is calculated from the predetermined maximum output power of the wind turbine according to the generator frequency. By neglecting the power loss and making the power balance between the optimum output power of the turbine defined by eq. 1 and the power supplied to the grid, the active current reference $i_{q s}^{*}$ of the grid-side inverter is defined as:

$$
i_{q s}^{*}=\frac{K_{o p t}}{V_{s}} f^{3} .
$$

However, $i_{q s}^{*}$ can be set easily by using a look-up table in the DSP program when the losses in the proposed system are considered. Based on the above principle, a control block diagram of the inverter is constructed as shown in Fig.1.

\section{B. Design Method of the Passive Filter}

Fig. 3 shows the $d-q$ axis equivalent circuits of the IPMSGside rectifier including the effects of the copper loss and the core loss of the generator. The core loss is expressed by an equivalent core loss resistance $r_{c}$ of $444.6 \Omega$. If $r_{c}$ is assumed to be a function of frequency, the hysteresis loss in addition to the eddy-current loss can be considered. From the equivalent circuit, the total losses $P_{\text {loss }}$ are expressed as follows:

$$
P_{\text {loss }}=r_{s}\left(i_{d}^{2}+i_{q}^{2}\right)+\frac{\left(v_{o d}^{2}+v_{o q}^{2}\right)}{r_{c}} .
$$




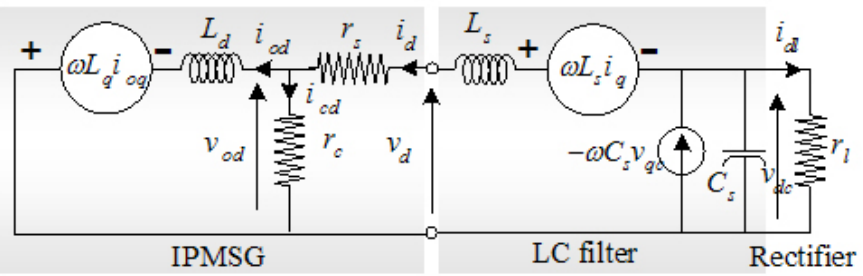

(a) $d$-axis equivalent circuit.

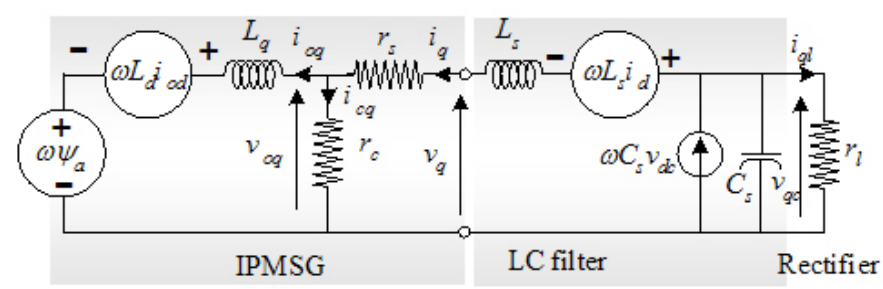

(b) $q$-axis equivalent circuit.

Fig. 3. Equivalent circuits of IPMSG-side rectifier.

The loss minimization of the IPMSG is obtained by setting the reactive exciting current $i_{d}^{*}$ to the desired value with a constant $i_{q}^{*}$ as defined by[16]:

$$
\begin{aligned}
& i_{d}^{*}=\frac{\sqrt{1.5} \phi_{a}}{2\left(L_{d}-L_{q}\right)} \frac{r_{s}+b(2-\gamma)}{r_{s}+b}+ \\
& \sqrt{\frac{1.5 \phi_{a}^{2}}{4\left(L_{d}-L_{q}\right)^{2}}\left(\frac{r_{s}+b \gamma}{r_{s}+b}\right)^{2}+i_{q}^{* 2} \frac{r_{s}+b \gamma^{2}}{r_{s}+b}}
\end{aligned}
$$

where $b=\frac{\left(\omega L_{d}\right)^{2}}{r_{c}}$ and $\gamma=\frac{L_{q}}{L_{d}}$.

Fig.4 shows the loss reduction versus the $d$-axis current of the $1.5 \mathrm{~kW}$ IPMSG used in the experiments. The power loss minimization is achieved in the range of $1 \mathrm{~A}$ to $2 \mathrm{~A}$ approximately. Therefore, the passive filter, set at the generator terminals, is designed not only to decrease the harmonic voltages and currents observed at the terminals of the IPMSG, but also to maintain the reactive current within the desired range in order to improve the generator efficiency. By ignoring the iron losses, the mathematical model of the IPMSG is defined in the $d-q$ synchronously rotating reference frame by the following equation [6]:

$$
\left[\begin{array}{l}
v_{d} \\
v_{q}
\end{array}\right]=\left[\begin{array}{cc}
r_{s}+p L_{d} & -\omega L_{q} \\
\omega L_{d} & r_{s}+p L_{q}
\end{array}\right]\left[\begin{array}{l}
i_{d} \\
i_{q}
\end{array}\right]+\left[\begin{array}{c}
0 \\
\sqrt{3 / 2} \omega \phi_{a}
\end{array}\right]
$$

The parameters of the passive filter are derived in the steadystate based on eq.10 by neglecting the armature resistance and assuming that the stator voltage is aligned on the $q$ axis. Applying these conditions at no-load, the stator reactive current of the capacitor $i_{d c}$ becomes:

$$
i_{d c}=-i_{d}=\omega C_{s} v_{q c}
$$

where $C_{s}$ is the filter capacitance. Under the same conditions, the $q$-axis capacitor voltage $v_{q c}$ becomes:

$$
v_{q c}=\omega\left(L_{d}+L_{s}\right) i_{d}+\sqrt{\frac{3}{2}} \omega \phi_{a} .
$$

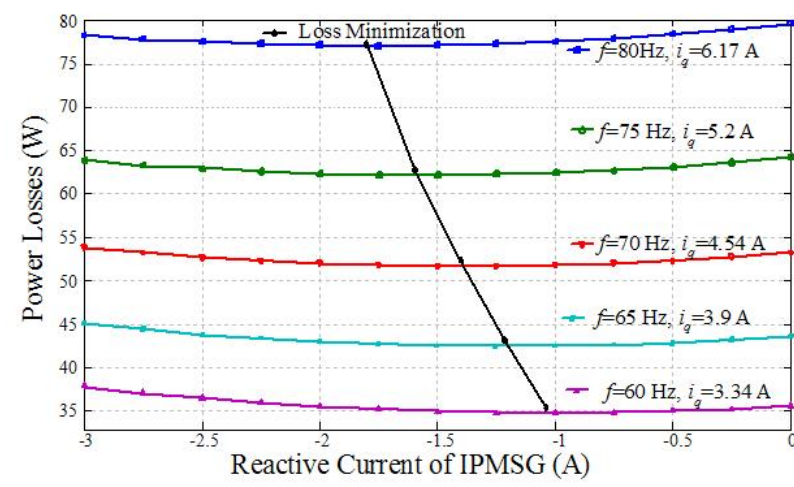

Fig. 4. Required reactive current of the IPMSG for power loss minimization.

TABLE I

SPECIFICATIONS OF THE $1.5 \mathrm{KW}$ IPMSG

\begin{tabular}{|c|c|c|}
\hline Components & \multicolumn{2}{|c|}{ Specifications } \\
\hline \multirow{4}{*}{ Interior } & Pair poles Number $P_{n}$ & 3 \\
\cline { 2 - 3 } & Magnet flux-linkage & $0.2878 \mathrm{~Wb}$ \\
Permanent & $\sqrt{3 / 2} \phi_{a}=\psi_{a}$ & \\
\cline { 2 - 3 } Synchronous & $q$-axis inductance $L_{q}$ & $11.96 \mathrm{mH}$ \\
\cline { 2 - 3 } Generator & $d$-axis inductance $L_{d}$ & $8.90 \mathrm{mH}$ \\
\cline { 2 - 3 } (IPMSG) & Armature resistance $r_{s}$ & $0.774 \Omega$ \\
\cline { 2 - 3 } & Maximum current $I_{a m}$ & $6.3 \mathrm{~A}$ \\
\cline { 2 - 3 } & Rated Power & $1.5 \mathrm{Kw}$ \\
\cline { 2 - 3 } & Rated Speed & $1750 \mathrm{rpm}$ \\
\cline { 2 - 3 } & Rated Voltage & $190 \mathrm{~V}$ \\
\hline
\end{tabular}

Then, substituting eq.12 into eq.11, the filter capacitance $C_{s}$ is defined simply by:

$$
C_{s}=\frac{-i_{d}}{\omega^{2}\left(L_{d}+L_{s}\right) i_{d}+\sqrt{3 / 2} \omega^{2} \phi_{a}} .
$$

By choosing a $7 \mathrm{mH}$ inductor and a $12 * 3 \mu \mathrm{F}$ capacitor calculated using eq.13, the passive filter is able to maintain the reactive current of the IPMSG close to the value required for power loss minimization and a reduction of the harmonics of the current and voltage.

\section{EXPERIMENTAL RESULTS}

The appropriate design of the passive filter without increasing the generator current constitutes a simple solution for both improving the generator efficiency and providing a good operating waveform performance while dealing with the series-type 12-pulse rectifier as a harmonics source.

The proposed MPPT control strategy has been applied and tested for a $1.5 \mathrm{~kW}$ IPMSG prototype set-up. The parameters of the proposed system are listed in Table I.

\section{A. Effect of the Designed Passive Filter}

The operating waveforms of the IPMSG system in terms of the IPMSG terminal voltage $v_{A B}$, the IPMSG stator current $i_{A}$, the grid line-to-line voltage $v_{V W}$, and the grid-side inverter current $i_{U}$ are shown in Fig.5. The operating waveforms are highly distorted if the passive filter is not used. Fig.5 indicates that the harmonic distortion observed in the generator current is $5.2 \%$ while the harmonic distortion of the generator voltages 


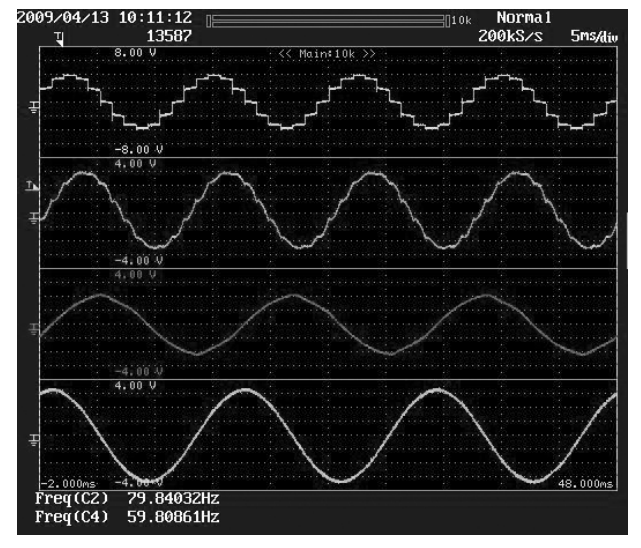

Fig. 5. Operating waveforms of the IPMSG system without passive filter.

Ch-1: IPMSG terminal voltage $v_{A B}-100 \mathrm{~V} /$ div. Ch-2: IPMSG stator current $i_{A}-2 A /$ div.

Ch-3: Grid voltage $v_{V W}-50 \mathrm{~V} / \mathrm{div}$

Ch-4: Grid-side inverter current $i_{U}-2.5 \mathrm{~A} / \mathrm{div}$.

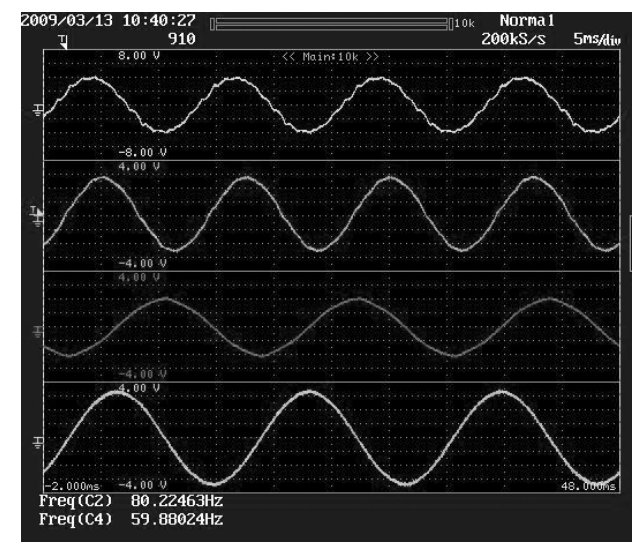

Fig. 6. Operating waveforms of the grid integration of the IPMSG system with passive filter at $80 \mathrm{~Hz}$.

Ch-1: IPMSG terminal voltage $v_{A B}-100 \mathrm{~V} / \mathrm{div}$.

Ch-2: IPMSG stator current $i_{A}-2 A /$ div.

Ch-3: Grid voltage $v_{V W}-50 \mathrm{~V} / \mathrm{div}$

Ch-4: Grid-side inverter current $i_{U}-2.5 \mathrm{~A} / \mathrm{div}$.

is $12.0 \%$. These harmonic distortions exceed the acceptable limits for high operating performance of the generator.

When the passive filter, represented by $L_{s}$ and $C_{s}$, is used together with a series-type 12-pulse rectifier, the harmonic distortion observed in the generator current is reduced from $5.2 \%$ to $3.1 \%$. At the same time, the harmonic distortion of the generator voltages is reduced from $12.0 \%$ to $5.0 \%$. Such reductions can be observed in Fig.6. The series-type 12-pulse rectifier powered by a phase shifting transformer with the designed passive filter shows its ability to reduce the total harmonic distortion (THD) of the generator.

It is possible to see the grid currents and voltages have a good operating waveform performance. The THD of the grid currents is less than $0.8 \%$, while the THD of the grid voltages $2.2 \%$.

Fig.7 compares the efficiency of a IPMSG having a passive filter connected at the ac side of a series-type 12 pulse rectifier with that of a IPMSG which uses a PWM rectifier. By minimizing the total losses of the IPMSG through a PWM rectifier, it is found that the passive filter as a low-cost solution provides an efficiency similar to the high cost solution. It

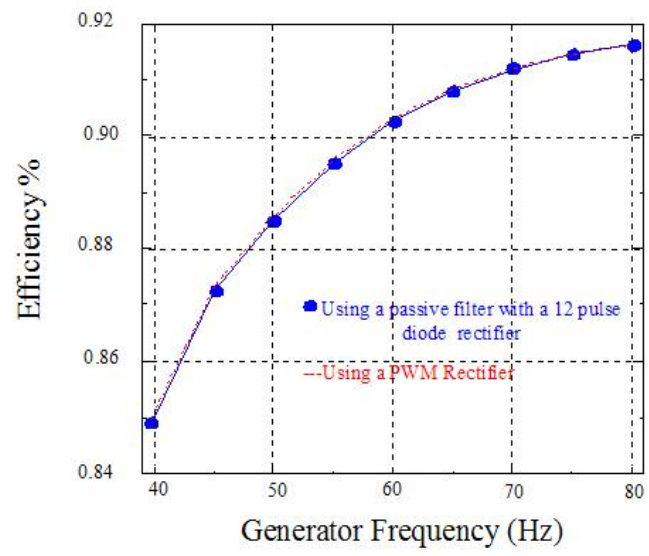

Fig. 7. Comparison in efficiency between the IPMSG with passive filter and the IPMSG with the PWM rectifier.

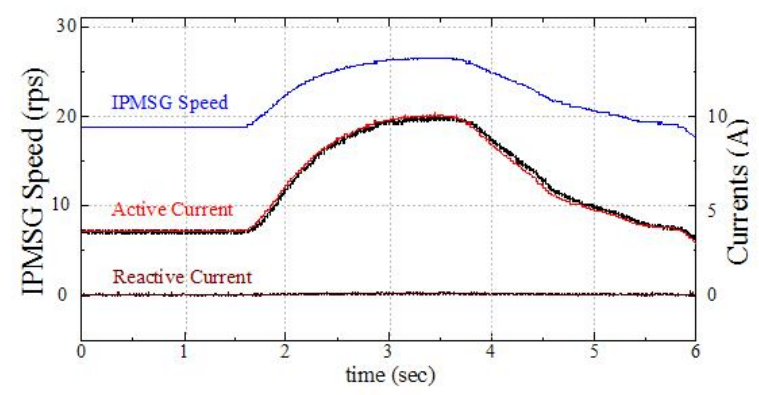

Fig. 8. Dynamic responses of the measured active and reactive currents of the grid-side inverter.

is concluded therefore that the passive filter together with a series-type 12-pulse rectifier provides high efficiency and suppresses the distortions present in the generator voltages and currents.

\section{B. Effect of the Proposed MPPT Strategy}

Fig.8 shows the dynamic responses of the measured active and reactive currents of the PWM inverter with speed variations. The reference for the $d$-axis or reactive current is set to zero for unity power factor operation, while the $q$-axis or active current and the active power are supplied to the power grid based on the MPPT control strategy. As the $d$-axis current is controlled to be zero, the peak envelop of the phase current $i_{U}$ is 0.816 times the magnitude of the $q$-axis current and power factor control is possible for the reactive power control.

It also keeps the THD as low as possible, thus improving the power quality supplied to the grid.

Fig.9 shows the estimated frequency error of the proposed MPPT control strategy in the steady-state, for a wide range of operating frequencies. The results indicate that the estimated error of the generator frequency using the proposed MPPT control method is less than $2 \%$.

Fig.9 also demonstrates the measured and reference active current of a PWM inverter with the proposed MPPT control method in comparison to the generator frequency in a wide frequency operation range. As the generator frequency changes 


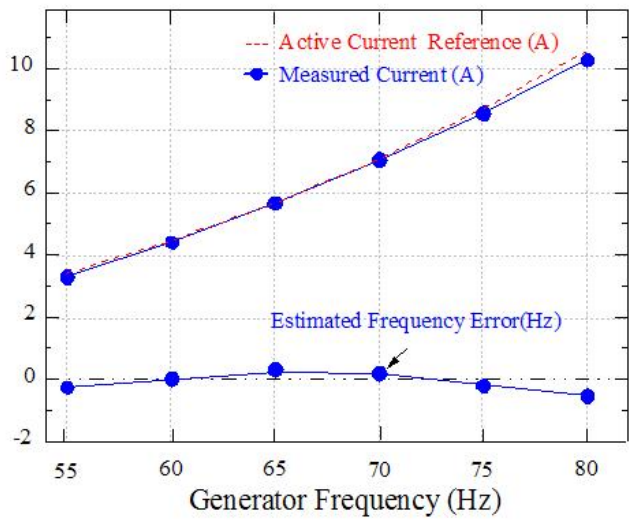

Fig. 9. Measured and reference active current of the grid-side PWM inverter with estimated frequency error of MPPT control method.

from 50 to 81 , the reference current changes accordingly in order to maximize the wind power output calculated from eq.7. The active current of the grid-side PWM inverter is adjusted to within a $2.5 \%$ error in order to achieve the proposed MPPT control strategy.

The results of the proposed system indicate that its construction and installation are simple, cheap, and efficient. Moreover, the IPMSG losses can be reduced as the designed passive filter draws a lag current in proportion to the square of the generator frequency.

\section{CONCLUSIONS}

In this paper, a novel and simple MPPT control strategy for a grid-side PWM inverter connected to a series-type 12 pulse rectifier for a variable-speed wind turbine has been proposed. As the proposed system requires only one inverter to attain MPPT control, the system cost can be reduced and a high reliability can be achieved. Moreover, the simple acdc converter employed with the IPMSG reduces the harmonic distortion of the generator while the dc-ac converter employed with the proposed MPPT control strategy supplies the maximum power of the wind turbine to the grid. The power factor of the grid-side inverter can be adjusted. The wind speed and/or generator frequency is measured from the rectified output voltage of the IPMSG and the maximum output power supplied to the grid. Therefore, the proposed control algorithm does not require any speed sensors for the wind or IPMSG speed. The laboratory results from the implementation of the simple ac-dc-ac power conversion circuit employed with the MPPT control algorithm indicate that the proposed system has advantages. These include cost-effectiveness, a wide frequency range, and flexible controllability of the active and reactive power to the grid when applied to a variable speed wind turbine controller.

In a future work, the voltage source inverter will be replaced by a current source inverter to allow the dc-link voltage to be varied widely with the wind speed variations. This may provide a low cost solution for grid-integration of a variablespeed wind turbine without the need for a dc-dc converter.

\section{REFERENCES}

[1] Siegfried Heier, Grid Integration of Wind Energy Conversion Systems, John Wiley \& Sons Ltd, 1998.

[2] M. Tazil, V. Kumar, R.C. Bansal, S. Kong, Z.Y. Dong, W. Freitas, and H.D. Mathur, "Three-phase doubly fed induction generators: An overview," IET Electric Power Applications, Vol.4, No. 2, pp. 75-89, Feb. 2010.

[3] J. Ribrant and L. M. Bertling, "Survey of failures in wind power systems with focus on swedish wind power plants during 1997-2005," IEEE Trans. on Energy Conversion, Vol. 22, No. 1, pp.167-173, Mar. 2007.

[4] N. A. Cutululis, E. Ceanga, A. D. Hansen, and P. Sørensen, "Robust multi-model control of an autonomous wind power system," Wind Energy, Vol.9, No.5, pp. 399-419, Sep./Oct. 2006.

[5] R.Pena, J.C.Clare, and G.M.Asher "Doubly fed induction generator using back-to-back PWM converters and its application to variable-speed wind-energy generation," IEE Electric Power Applications, Vol.143, No.3, pp.231-241, Feb. 1996.

[6] S. Morimoto, T. Nakamura, and Y. Takeda, "Power maximization control of variable-speed wind generation system using permanent magnet synchronous generator," IEEJ Trans. on Power and Energy, Vol. 123-B, No.12, pp.1573-1579, Dec. 2003.

[7] K. Nishida, T. Ahmed, and M. Nakaoka, "Induction generator hybrid applications with active power filter," IET Proceedings, Electric Power Applications, Vol.153, Issue 2, pp.197 - 205, Mar. 2006.

[8] T. Ahmed, K. Nishida, and M. Nakaoka, "Advanced control of PWM converter with variable-speed induction generator," IEEE Trans. on Industry Applications, Vol.42, Issue 4, pp.934 - 945, Jul./Aug. 2006.

[9] T.F. Chan, W. Wang, and L.L. Lai, "Analysis and performance of a permanent-magnet synchronous generator supplying an isolated load," IET Electric Power Applications, Vol.4, No. 3, pp.169-176, Mar. 2010.

[10] L.Grzesiak, W.Koczara, M. da Ponte "Application of a permanent magnet machine in the novel hygen adjustable-speed load-adaptive electricity generating system," International Conference IEMD '99, pp.398-400, 1999.

[11] K. Tan and S. Islam, "Optimum control strategies in energy conversion of PMSG wind turbine system without mechanical sensors," IEEE Trans. on Energy Conversion, Vol.19, No.2, pp.392-399, Jun. 2004.

[12] S. Jiao, G. Hunter, V. Ramsden and D. Patterson "Control system design for a $20 \mathrm{~kW}$ wind turbine generator with a boost converter and battery bank load," 32nd Power Electronics Specialists Conference(PESC) 2001, Vol.4, pp.2203-2206, 2001.

[13] S.Song, S.Kang, and N.Hahm, "Implementation and control of grid connected AC-DC-AC power converter for variable speed wind energy conversion system," 18th Annual IEEE APEC03, Vol.1, pp.154-158, 2003.

[14] Y.Higuchi, N.Yamamura, M.Ishida, T.Hori "An improvement of performance for small-scaled wind power generating system with permanent magnet type synchronous generator," 26th Annual Conference of the IEEE - IECON 2000,Vol.2, pp.1037-1043, 2000.

[15] R. Hoffmann, P. Mutschler, "The influence of control strategies on the energy capture of wind turbines," 2000 IAS Conference Record, pp.886 - 893, 2000.

[16] C. Mademlis and N. Margaris, "Loss minimization in vector-controlled interior permanent-magnet synchronous motor drives," IEEE Trans. on Industrial Electronics, Vol.49, No.6, pp.1344-1347, Dec. 2002.

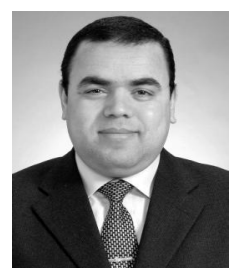

Tarek Ahmed received his Ph.D. in Electrical Engineering from Yamaguchi University, Japan in 2006. Since 2009, he has been conducting research within the Renewable Energy Research Group at the University of Exeter in the area of wave energy development to create a major grid-connected project off the north coast of Cornwall, UK. In addition, he is a Lecturer in the Electrical Engineering Department, Faculty of Engineering, Assiut University, Assiut, Egypt. Dr. Ahmed joined the Assiut Engineering faculty in 1995, as an Instructor. In 1998, on completion of his master's degree, he was made a Teaching Assistant in the Department of Electrical Power and Machines within the same department. His research interests include power electronics and electric machine control for grid integration of renewable energy. Dr. Ahmed has received the best paper awards from the Institute of Electrical Engineers of Japan in 2003, 2004, and 2005. He has also received the best paper and student awards from the 30th Annual Conference of the IEEE Industrial Electronics Society, 2004, the best paper award from the International Conference on Electrical Machines and Systems, 2004 and the best paper award from the 8th IEEE International Conference on 
Power Electronics and Drive Systems, 2009. Dr. Ahmed is a member of the Institute of Electrical and Electronic Engineers and has been widely published in many international journals.

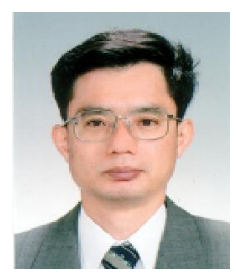

Katsumi Nishida was born in Yamaguchi, Japan, in 1954. He received his B.S., and M.S. in Electrical Engineering from the Tokyo Institute of Technology, Tokyo, Japan, in 1976, 1978, respectively, and his Ph.D. in Electrical Engineering from Yamaguchi University, Ube, Japan, in 2002. He is currently a Professor with the Department of Electrical Engineering, Ube National College of Technology, Ube. His research interests are in the design and control of power conditioners with the deadbeat technique and the adaptive signal processing technique. Prof. Nishida has received the best paper awards from the 8th IEEE International Conference on Power Electronics and Drive Systems, 2009. Prof. Nishida is a member of the Institute of Electrical Engineers of Japan (IEE-Japan), the Power Electronics Society of Japan and the Institute of Installation Engineers of Japan.

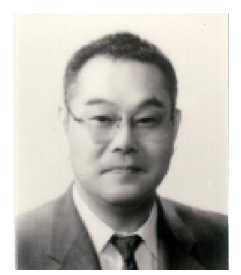

Mutsuo Nakaoka received his Ph.D. in Electrical Engineering from Osaka University, Suita, Japan, in 1981. He joined the Department of Electrical and Electronics Engineering, Kobe University, Kobe, Japan in 1981. Since 1995, he had been a Professor with the Department of Electrical and Electronics Engineering, Graduate School of Science and Engineering, Yamaguchi University, Ube, Japan. He is currently a Visiting Professor with the Electrical Energy Saving Research Center, Kyungnam University, Masan, Korea. His research interests include state-of-the-art power electronics circuits and systems engineering. Prof. Nakaoka received many distinguished paper awards such as the 2001 Premium Prize Paper Award from IEE-UK, the 2001/2003 IEEE IECON Best Paper Award and the Third Paper Award from the 2000 IEEE PEDS as well as the 2003 IEEE-IAS and the best paper award from the 8th IEEE International Conference on Power Electronics and Drive Systems, 2009. 